\title{
Competitiveness of trade enterprises in building and finishing materials' market in pandemic conditions
}

\author{
Olga Kovalenkova and Oksana Khlopenko* \\ Don State Technical University, 344000, Rostov-on-Don, Russia
}

\begin{abstract}
The article examines the impact of new economic conditions against the backdrop of the COVID-19 pandemic on the trade enterprises competitiveness using the example of the market of building and finishing materials. The aim of the study is to identify the qualities that a manager, who is able to bring an enterprise out of a crisis state with the least consequences for it, should possess, to develop a model for managing the competitiveness of trade enterprises by forming a set of corrective measures aimed at ensuring the competitiveness of services accompanying the trade in construction and finishing materials. Theoretical studies were carried out using the methods of system analysis and generalization of the existing scientific developments in the field of managing the trade enterprises' competitiveness [1]. The methods of statistical analysis were used to determine the crisis impact assessment on the competitiveness of trade enterprises and to identify the competitive advantages of the industrial analyzed segment. As a result of the study, the following results were obtained.: - analysis of trends in the retail industry revealed the main problems of trade enterprises in the context of the crisis caused by the spread of a new coronavirus infection; - the use of the fundamental principles of the formation and maintenance of the organization's competitive advantages made it possible to determine the competitive advantages of trading enterprises in the market of building and finishing materials, using digital technologies in business, allowing to maintain a stable position in industrial market; - relying on a system of long-term competitive advantages, the main activity areas of trade enterprises were identified, which, thanks to corrective solutions, are able to ensure sustainable development in the context of overcoming the crisis caused by the COVID-19 pandemic.
\end{abstract}

\section{Introduction}

Trade is one of the main economy directions in any country. Over the last period of the Russian economy development, the nature of the trading industry has changed dramatically. Such formats as retail chains, super- and hypermarkets were rapidly gaining momentum. In a pandemic, there is a sharp shift towards e-commerce, an increase in the number of online

\footnotetext{
* Corresponding author: olga.kovalenkowa@yandex.ru
} 
sales, and the creation of marketplaces. The intensive development of trade enterprises and trade in general has led to serious consequences associated with the competition intensification in the industry. This situation required a revision of the development strategy of enterprises, the introduction of new forms of organization and business management in order to maintain and increase the market share. Based on the foregoing, the subject of the study is the development of trade enterprises in the current macroeconomic conditions in the building materials market.

The study showed that the introduction of innovative technologies in trade and technological processes, assortment policy, inventory management of trade enterprises significantly increases the competitiveness and efficiency of their activities.

\section{Methodology}

In the course of the study, the following methods were used: categorical, comparative analysis and synthesis based on the integration of theories and concepts, scientific works devoted to the problems of managing the competitiveness of trade enterprises.

The categorical analysis was used to identify the content of the " competitiveness management" concept, comparative analysis - in comparing the indicators of retail turnover for 2020, synthesis - in identifying and generalizing the patterns of a particular industry development.

The research is based on official statistics data, materials contained in the articles of Russian and foreign economists, periodicals.

\section{Results}

\subsection{The main trends in the retail industry during the COVID - 19 pandemic}

In the current situation, under the influence of the changes caused by the COVID - 19 pandemic, trade enterprises are faced with the previously unknown problems. The COVID19 pandemic has forced many retailers to reorganize their activities to adapt to the new conditions [2-5].

According to Rosstat and the Ministry of Industry and Trade of Russia, the fall in retail turnover in April 2020 amounted to $23.4 \%$ in annual terms, in May - more than 19\%, in June - almost $8 \%$, in July - about 3\%, in August - by 2\%, 7\% and in September - by another $3 \%$. In January-September 2020, sales were $4.8 \%$ lower than last year.

Trade enterprises, which assortment consists mainly of food and related products, were able to continue their work, however, the dynamics of their performance indicators makes it possible to single out several stages [3].

The first stage fell on March 2020, and was accompanied by emergency purchases by the population of long-term storage products (cereals, canned food, pasta, vegetable oil, etc.) and the introduction of enhanced anti-epidemiological measures in retail outlets, regardless of the enterprises format. However, this did not lead to an increase in the trade enterprises revenue, following the March rush in April, an increase in the volume of onetime purchases followed.

At the second stage (April - June 2020), retailers had to face access the regimes at the borders of the regions, which was a violation of the schedules for the supply of goods from other regions and territories. This was followed by the introduction of mask regimes by the regions and difficulties both in ensuring at the initial stage a sufficient supply of masks in the trade assortment and in terms of interaction with buyers who violate the authorities' regulations. 
In the food trade segment, in the crisis conditions of the pandemic, shops of small and medium-sized businesses of various formats were affected, which affected the economic indicators of their activities. One of the factors that influenced the situation worsening is the flow of buyers to chain stores. Forced restrictions in the activities of trade enterprises have increased the costs of anti-epidemiological measures, personnel, logistics activities, etc. [5].

In general, trade in food products in January-August 2020 lost about $2.2 \%$ of turnover compared to the same period in 2019 , although large retail chains managed to maintain and even increase turnover.

Trade in non-food products, due to the restrictions imposed, was forced to suspend the operations at its facilities in March 2020, and only from June it gradually restores business processes, incurring significant additional costs associated with a set of measures to prevent the emergence of a new coronavirus infection [6].

In the structure of DIY market, a large share belongs to the commodity groups of building and finishing materials; their sales during the pandemic did not quite correspond to the general trends. A number of products were unavailable to customers during the strict restriction period from March to August 2020. However, according to the experts of the Russian market of building materials and tools, there was no significant shortage of building and finishing materials due to the COVID-2019 pandemic. Interruptions in the supply of goods for the repair and reconstruction of residential premises from abroad were painlessly replaced by the domestically manufactured products [7].

Small and medium-sized enterprises in the field of trade in construction and finishing materials suffered losses due to fierce competition with construction hypermarkets. Large enterprises, for example, "Leroy Merlin", "Castorama" and others, did not suffer serious financial losses in comparison with small retail outlets. Nevertheless, in the trade segment in construction materials, there is a simultaneous tightening of competition among retail chains. Leroy Merlin hypermarket is the undisputed leader absorbing small retail outlets of the "near home" format, which continues to increase its market share. In the crisis economic conditions, companies won that were able to quickly respond to the current situation with the active development of online sales [8].

Among the manufacturers of building and finishing materials, who are suppliers of small and large trade enterprises in the Russian market, there has also been an increase in competition recently, in particular for the sale of finished products [9].

Active consumer demand in the segment of construction, finishing and paints and varnishes, especially during a pandemic, prompted domestic manufacturers of these goods to expand the range, improve quality, use modern high-performance equipment, in order to reduce costs, introduce new technologies for sales, supplies and settlements with consumers.

To maintain their positions in the competitive field of the building and finishing materials market, using the existing and creating the new competitive advantages, trade organizations digitalize the implemented business processes [10].

\subsection{Development of online commerce as a factor in increasing competitiveness}

To rebuild and develop the key competitive success factors, merchants, in particular the construction retail outlets, need to expand their e-commerce sales channel, powered by advanced digital technologies.

During the COVID-19 pandemic, which determined the new economic conditions of management, one of the sales channels for construction and finishing materials, namely, retail chains in the DIY market, has noticeably changed. Leading positions were taken by the trade companies, which before the crisis were actively developing online sales based on 
the omnichannel principle, which allowed them to respond flexibly and quickly to the current situation, increase delivery speed and significantly increase their turnover. Some manufacturers, noticing this trend, thought about increasing the sales share through this channel [11].

During self-isolation, it became clear to many entrepreneurs that distance selling was the decisive word, which would help maintain a competitive position in the industry market. Accordingly, large and medium-sized businesses must carry out digital transformation at an accelerated pace in order to retain their customer audience.

The crisis situation violated the plans of the consumer, who suddenly lost the ability to freely visit trade enterprises and make purchases, to carry out the construction and repair works. Consequently, the audience of online stores has grown significantly. It can be said that retailers and consumers have a unique opportunity to adapt to online shopping, and telecommuting.

Self-isolation period has forced many consumers to familiarize themselves with the ecommerce possibilities, which has brought millions of new users to Russian e-commerce services. According to experts, the audience has grown by an average of 5-10 million people. It should be noted that these are exactly those buyers who have never before practiced online shopping and have not used online resources [12].

To retain its audience, e-commerce must offer its customers an exceptional service and special conditions, including, for example, fast delivery or prices lower than in offline stores, fast and easy payment methods.

With the correct operation of marketing, trade and information tools, it is possible not only to maintain the previous level of sales, but also to increase it, which means that there will be a need to improve the logistics system of a trading enterprise to provide a high level of service, which has become crucial [13]. In the new reality, a new situation is emerging: it is not the buyer who comes to the seller, but vice versa.

\subsection{Features of competitiveness management in the industry market}

It is impossible to rely on marketing and information technology alone in pandemic conditions. In the face of global uncertainty, a trading enterprise needs a competitiveness management model that will help minimize losses or improve existing performance indicators by wisely using financial, human, digital and information resources.

It is necessary to highlight the following qualities that a leader must possess, capable of leading an enterprise into a crisis with minimal consequences for it [14].

First, a competent leader must adhere to a rational position to keep the financial performance of the enterprise at the current level against the background of some indulgences that accompany the events of this kind.

Second, effective leaders must correctly prioritize and stabilize the situation in the team of employees, maintaining a formed corporate culture to overcome the current crisis, while monitoring opportunities for business development in difficult conditions.

Third, business leaders prioritize the response speed to market changes before completeness of information, because they understand that in an emergency, it is necessary to respond quickly.

Fourth, the effective managers must fully take the situation under control, thereby ensuring transparency of information, instilling confidence in the personnel of the enterprise, skillfully presenting opportunities for the trading enterprise further development.

And finally, fifth, a competent manager understands that the pandemic will end sooner or later and looks at the long term, trying to predict what business models may be in demand in the future.

One of the most important competitiveness properties of the enterprises trading in non- 
food products, and in particular construction and finishing materials, is the ability to manage it regardless of the prevailing economic situations in the industry markets. This property opens up the new reserves in the field of competitiveness formation at the enterprise level.

\subsection{The business model of managing the trading enterprise competitiveness.}

Based on the considered factors affecting the trade enterprise competitiveness management, as well as based on the enterprises' operation specifics in the market of building and finishing materials during the COVID-19 pandemic, a business model for managing the competitiveness of a trade enterprise has been built (Figure 1).

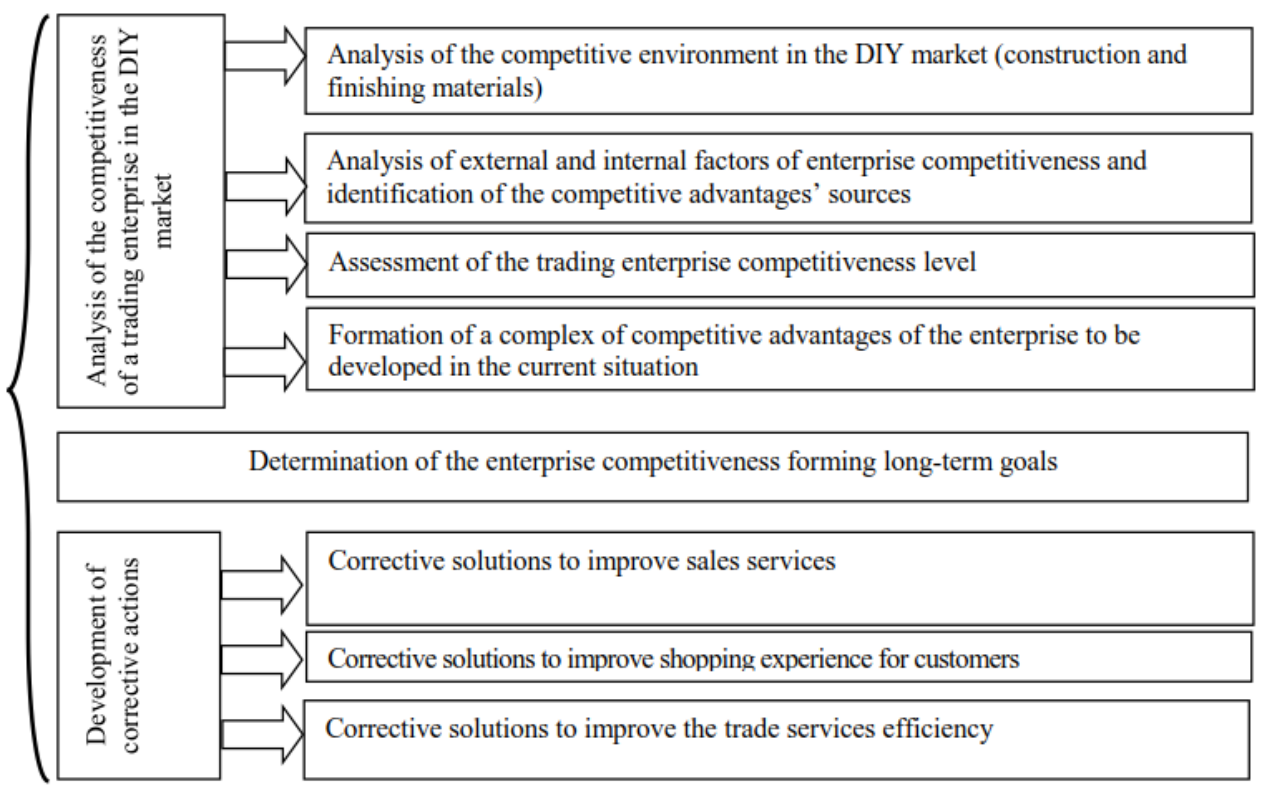

Fig. 1. The model of managing the competitiveness of a trading enterprise in the new economic conditions

The proposed model consists of three stages:

1. Analysis of the trading enterprise competitiveness in the DIY market.

2. Determination of long-term goals of forming the enterprise competitiveness.

3. Development of corrective measures to maintain the competitiveness level of a trading enterprise.

Let us consider each stage of the model for managing the competitiveness of a commercial enterprise in the building materials market.

Stage 1. Competitiveness analysis of a trading company in the DIY market with construction and finishing materials.

The competitive environment should be subjected to detailed analysis, that is, in our opinion, it is important to analyze the competitive structure of the market for building and finishing materials: the ability of suppliers to use modern trading technologies and the ability of buyers to accept the new terms of trade, rivalry between the sellers - competitors, identification of new competitors, goods and services.

In turn, the analysis of the internal and external environment, SWOT - analysis will show the sectoral potential of a trading enterprise, its ability to maintain an optimal level of competitiveness, sources and criteria of competitive advantages, factors and prospects for 
their formation.

Assessment of the competitiveness level of a trade enterprise in the market of building and finishing materials will determine the directions of its increase in a constantly changing economic environment.

The result of the enterprise competitiveness analysis is the substantiation of its real competitive advantages, as well as the development of a system of measures to form potential medium and long-term competitive advantages.

Stage 2. Determination of long-term goals of forming the enterprise competitiveness.

The trading enterprise competitiveness management should be based on the long-term goals of forming the enterprise competitiveness in the framework of the long-term goals of the organization's development. At this stage, it is necessary to build a tree of goals for the enterprise competitiveness formation.

Stage 3. Development of a strategy to ensure the enterprise competitiveness

The trading enterprise competitiveness indicator in the market of building and finishing materials is complex and includes a high level of the offered goods and trade services competitiveness. Thus, at the stage of developing a strategy for ensuring competitiveness, it seems expedient to develop corrective measures to ensure a high level of competitiveness of trading services related to the sale of goods, as well as pre-sale and after-sales services to consumers, including the following:

1) development of measures to improve services for the sale of goods, covering the solutions in the field of forming an assortment of building and finishing materials for organizing distance selling, organizing a trade and technological process at an enterprise;

2) development of corrective measures to improve shopping services for the customers, including a set of solutions in the field of ensuring the comfort of consumers receiving goods and trading services;

3) development of corrective measures to improve the efficiency of trade services, covering the solutions in terms of the enterprise after-sales services complex formation, their packaging and ensuring conditions for maximum availability for consumers.

On the basis of the formed program of corrective measures, a complex of management decisions is developed in the field of marketing, logistics, financial activities of a trade organization, as well as in the field of personnel management $[15,16]$.

Thus, the proposed refined model for managing the competitiveness of a trading enterprise in the DIY market in the segment of trade in construction and finishing materials in modern economic conditions is aimed at ensuring the maintenance of the competitiveness of the enterprise, the flexibility of its business model, due to the need to respond quickly to changes in market conditions and improve the efficiency of business management decisions' adoption.

\section{Conclusion}

The coronavirus pandemic and the ensuing economic crisis had a significant impact on the building materials market, identifying modern vectors for the trade development of the various levels' enterprises, accelerating technological transformations, the introduction of digital information technologies and increasing competition in the field of trade.

Flexibility and responsiveness come to the fore, the need to act in conditions of uncertainty, which requires the formation of new competencies among managers of trade enterprises, in particular, to have the developed meta-skills when making managerial decisions.

A systematic analysis of the enterprise competitiveness, maintaining and searching for the new competitive advantages, defining a behavior strategy in order to maintain and possibly increase market share, developing corrective measures to ensure competitiveness 
are the main guidelines for achieving results and strengthening the market position in modern conditions.

\section{References}

1. N. Tyukhtenko, S. Makarenko, N. Oliinyk, \& E. Portugal, Marketing and Management of Innovations 1, 278-289 (2021) doi: 10.21272/mmi.2021.1-21

2. Maria Nicola, Zaid Alsaf, Catrin Sohrabi, Ahmed Kerwan, Ahmed Al-Jabir, Christos Iosifidis, Maliha Agha, Riaz Agha,. International Journal of Surgery Available online 78, 185-193 (2020). doi:10.1016/j.ijsu.2020.04.018

3. Andreas Kuckertz, Leif Brandle, Anja Gaudig, Sebastian Hinderer, Carlos Arturo Morales Reyes , Alicia Prochotta , Kathrin M. Steinbrink, Elisabeth S.C. Berger, Journal of Business Venturing Insights 13, e00169 (2020) doi:10.1016/j.jbvi.2020.e00169

4. Abid Haleem, Mohd Javaid, Raju Vaishya, S.G. Deshmukh, The American Journal of Emergency Medicine Available online 38 (7), 1524-1526 (2020) doi:10.1016/j.ajem.2020.04.022

5. Roberto Mora Cortez, Wesley J. Johnston, Industrial Marketing Management Available online 88, 125-135 (2020) doi:10.1016/j.indmarman.2020.05.004

6. I.Y. Zilberova, P.A. Shumeev, I.V. Novoselova, IOP Conference Series: Materials Science and Engineering 913, 052025 (2020) doi:10.1088/1757-899X/913/5/052025

7. R.S. Khan, V.V. Surkov, A.A. Fedosenko, O.A. Olatalo, IOP Conference Series: Materials Science and Engineering 913, 052013 (2020) doi:10.1088/1757899X/913/5/052013

8. E.N. Rudskaya, I.A. Eremenko, IOP Conference Series: Materials Science and Engineering 913, 052011 (2020) doi:10.1088/1757-899X/913/5/052011

9. N.V. Gontar, A.G. Sapozhnikova, IOP Conference Series: Materials Science and Engineering 913, 052001 (2020) doi:10.1088/1757-899X/913/5/052001

10. K.A. Barmuta, E.M. Akhmetshin, I.Y. Andryushchenko, A.A. Tagibova, G.V. Meshkova, A.O. Zekiy, Entrepreneurship and Sustainability 8 (1), 945-959 (2020) doi: 10.9770/jesi.2020.8.1(63)

11. N. Serbulova, T. Morgunova, G. Persiyanova, E3S Web of Conferences 210, 02005 (2020) doi:10.1051/e3sconf/202021002005

12. Y. Medvedeva, E3S Web of Conferences 210, 13042 (2020) doi:10.1051/e3sconf/202021013042

13. N.A. Saveleva, et al., Artificial Intelligence: Anthropogenic Nature vs. Social Origin. ISC Conference. Advances in Intelligent Systems and Computing 1100, 104-110 (2020). doi:10.1007/978-3-030-39319-9_11

14. Charles H. Schwepker, Journal of Business-to-Business Marketing 26 (2), 1-18 (2019) doi:10.1080/1051712X.2019.1603358

15. Alexey A. Kuzubov, Aleskandr N. Maksimenko, Oksana V. Khlopenko, Margarita N. Bezuglova, Revista Espacios 42 (02), 61-70 (2021) doi: 10.48082/espaciosa21v42n02p06

16. E. Rudskaia, I. Eremenko, S. Tekucheva and O. Kovalenkova, E3S Web of Conferences 164 (2), 09038 (2020) doi:10.1051/e3sconf/202016409038 